\title{
Screening, Isolation and Evaluation of Secondary Metabolite Producing Streptomyces against Spider Mite, Tetranychus urticae on Okra
}

\author{
Rajesh Ramasamy ${ }^{*}$ Jaivel Nanjundan and Marimuthu Ponnusamy
}

\author{
Department of Agricultural Microbiology, Tamil Nadu Agricultural University, \\ Coimbatore 641 003, Tamil Nadu, India \\ *Corresponding author
}

\section{A B S T R A C T}

Keywords

Screening, Isolation and evaluation,

Secondary metabolite.

Article Info

Accepted:

24 September 2017

Available Online:

10 November 2017
A survey was conducted in Tamil Nadu and Maharashtra to isolate the actinomycetes from the soil samples for study. Twenty seven cultures of actinomycetes were isolated, purified and designated as actinomycetes (A1 to A27). The test cultures A1 to A27 were taken for studying their acaridical activity. Preliminary screening revealed that five of the isolates were active against spider mite, Tetranychus urticae on okra. Out of the sixteen isolates A7 and A27 isolate showed highest activity against red spider mite, Tetranychus urticae. The elite isolate A7 and A27 was selected for further study. From the isolates only A7 showed maximum antimicrobial activity. This A7 isolate was selected and used for the present study to control red spider mite. Based on the mycelial and cellular morphology of A7 isolate observed under phase contrast microscope (100X), the actinomycete isolate was identified as Streptomyces fradiae. The 16s $\mathrm{r}$ DNA gene sequence A7 was found to be 98 per cent similar to $S$. fradiae. The $16 \mathrm{~s}$ r DNA gene sequence A27 was found to be 98 per cent similar to $S$. fradiae. The phylogenetic tree obtained by applying the neighbourjoining method.

\section{Introduction}

Actinobacteria are heterogenous group of microorganisms holding unicellular as well as filamentous organisms (Tanaka and Omura, 1993). Actinomycetes are present in huge numbers in soil. They form the majority of microbial load of the agricultural, compost and garden soils. The genus Streptomyces is represented in nature by the largest number of species and varieties among the family Actinomycetaceae (Kanzaki et al., 2000). They differ greatly in their morphology, physiology and biochemical activities, producing the majority of known enzymes (Suneetha and Zaved, 2011). Among the genera of Actinomycetes, the genus streptomyces is represented in nature by the largest number of species and varieties, which differ greatly in their morphology, physiology and biochemical activities. Interestingly, the majority of the antibiotic-producing Actinomycetes are found among those species, which led to a growth in economic importance for this group of organisms (Kulkarni and Aynihojri, 1995).

Mites belong to the phylum Arthropoda, Arachnida Class, Acari Subclass. There are around 500,000 species of mites in the world, being the most diverse species in Arthropoda. Mites can be classified into phytophagous, 
predaceous, parasitical, haematophagous, saprophagous, coprophagy or fungivorous in nature. Mites have diverse shapes, propensities and habitats. Their traces can be found nearly everywhere in the world, even on pulmonarius and oyster mushrooms and peoples' faces. That's why miticides are in great demand. Acaricides are pesticides for the control of mite pests, which can only or mainly control mites. Mite is an important agricultural pest with a global distribution. Its phytophagous nature, high reproductive potential and short life circle facilitate rapid resistance development to many acaricides often after a few applications. The Actinobacteria are a morphologically, physiologically and ecologically diverse group of bacteria. Absolute majority of antibiotic-producers are encountered among these species making them economically potent. Keeping in view the significant contribution of Actinobacteria in the areas of soil ecology and industrial exploitation, an attempt has been made to isolate and identify potential Actinobacteria from Tamil Nadu and Maharastra. Based on these characteristics, the two dominant Actinobacteria strains were identified as Streptomyces fradiae which could be further utilized for acaricidal activity against spider mite, Tetranychus urticae on okra.

\section{Materials and Methods}

\section{Sample collection}

The soil samples taken for this study were collected from two different locations i.e. Maharashtra and Tamil Nadu in August.

\section{Isolation of actinomycetes}

Actinomycetes were isolated by pour plate technique following the serial dilution $\left(10^{-3}\right.$ and $10^{-4}$ ) of soil samples on Ken Knights medium. Actinomycetes isolates were selected for preliminary screening by cross streak method for antibacterial activity and the twenty six isolates of actinomycetes designated as (Actinobacteria) A1, A2, A3, A4, A5, A6, A7, A8, A9, A10, A11, A12, A13, A14, A15, A16, A17, A18, A19, A20, A21, A22, A23, A24, A25, A26 and A27. Selected colonies (rough, chalky, dry) of actinomycetes were further isolated in pure form on the solidified Ken Knight Agar medium by streak plate method. Colony selection was based on the colour of the aerial and substrate mycelia, difference in morphology and rate of growth.

\section{Cultural characteristics of actinomycetes culture on different media}

The actinomycetes culture were streaked on different medium viz., Nutrient agar, Yeast extract agar, Ken Knight's agar, Kuster's agar, Crawford's agar. The ISCC-NBS Colour-Name charts illustrated with centroid detection of the aerial, substrate mycelia and soluble pigment (Kenneth and Deane, 1955) was used.

\section{Biochemical characterization}

The seven isolates of the actinomycetes were used for biochemical studies (Ellaiah et al., 1996). The various biochemical tests (catalase, Casein hydrolysis, Starch hydrolysis, Indol activity and Triple Sugar Iron (TSI) agar test) were performed for the identification of the potent isolates. All the cultures were incubated at $28^{\circ} \mathrm{C}$ for $24-48$ hours.

\section{Starch hydrolysis}

Actinomycetes isolate was streaked on solidified starch agar medium and incubated for 5 days. The Petriplate was flooded with iodine solution for 30 seconds after incubation and drained. The amylase positive 
activity was indicated by the formulation of yellow zone around the colonies.

\section{Gelatin hydrolysis}

Actinomycetes isolate was tested for the production of gelatinase, which is proteolytic exo enzyme and capable of hydrolyzing gelatin. Solidified gelatine agar plates were streaked with the actinomycetes isolates and incubated for 5 days at $30^{\circ} \mathrm{C}$. Hydrolysis was confirmed by flooding the plates with mercuric chloride solution.

\section{Casein hydrolysis}

The isolate were streaked on skim milk agar plates and incubated at room temperature for 5 days.

Hydrolysis of casein was confirmed by flooding the plates with mercuric chloride solution and the plates were observed for the presence of clear zone surrounding the colonies and considered for positive reaction.

\section{Hydrogen sulfide production test}

Sulfide indole motility (SIM) agar deep tubes were stab inoculated with actinomycetes isolates and incubated at $35^{\circ} \mathrm{C}$ for $4-5$ days. Black colouration along the line of stab inoculation indicates $\mathrm{H}_{2} \mathrm{~S}$ production. Hydrogen sulphide production was carried out according to (Cowan, 1974).

\section{Indole production test}

The actinomycetes isolates were inoculated into glucose tryptone broth and incubated for 5 days. About $0.3 \mathrm{ml}$ of Kovac's reagent was added and mixed well.

After incubation, the reddening of the alcohol layer within a few minutes indicates indole production by the culture.

\section{Methyl red Voges Proskauer test}

MR-VP tests were performed to differentiate bacteria that produce acid from those that produce acetoin, a neutral product. The actinomycetes isolates were inoculated into MR-VP broth and incubated at $35^{\circ} \mathrm{C}$ for $4-5$ days. The positive Methyl red test was indicated by change in colour of broth from yellow to red by the addition of methyl red indicator after incubation. Positive test of Voges Proskauer was indicated by the development of red colour in MRVP broth by addition of Baritts' reagent.

\section{Urease test}

Urease test of actinomycetes isolates was performed on urea agar containing the $\mathrm{pH}$ indicator phenol red. The actinomycetes isolates were inoculated and incubated for 5 days. The development of red colour in the broth indicates the positive reaction for the test.

\section{Inoculation of fermentation broth}

The Soluble Starch (SS) broth was prepared. One litter Erlenmeyer flasks sterilized by autoclaving at $121{ }^{\circ} \mathrm{C}$ and $15 \mathrm{lb}$ for 15 minutes. After the broth cooled, $100 \mathrm{ml}$ volumes of actinomycetes suspensions were used to inoculate the flasks. The flasks were then incubated at $27{ }^{\circ} \mathrm{C}$ for 10 days. For quality control, confirmation of purity was done by streaking the fermentation cultures on nutrient agar (NA), potato dextrose agar (PDA) and ken knight agar plates.

\section{Solvent extraction of culture filtrate}

The antimicrobial compounds from crude extract were extracted with five different solvent viz., methanol (high polar), chloroform (medium polar), ethyl acetate (medium polar), Petroleum ether (non-polar) 
and Hexane (non-polar). To evaluate which particular solvent dissolves more secondary metabolites from crude extract. Solvents was added to the filtrate in the ratio of $1: 1(\mathrm{v} / \mathrm{v})$ and shaken vigorously for $1 \mathrm{~h}$ for complete extraction.

Then with help of separating funnel the ethyl acetate phase that contains antibiotic was separated from the aqueous phase. The aliquot was concentrated in vacuo at $60{ }^{\circ} \mathrm{C}$ using a rotary flash vacuum evaporator.

\section{Mass production of A7 and A27 isolate}

The A7 and A27 mother culture was inoculate on the Ken Knight's broth and incubated at 28 ${ }^{\circ} \mathrm{C}$ for 4 to 7 days under aerobic conditions. Mass production of A7 and A27 culture carried out using soluble starch medium.

The production medium inoculated with A7 and A27 culture at 5 percent level. The flasks were incubated at room temperature for 6-7 days.

\section{Method of bioassay}

For studying the acute toxicity of A7 and A27 isolateagainst $T$. urticae, unifested leaves collected from okra plants were cut into pieces of $40 \mathrm{~mm}$ dia. size and dipped in acaricide solutions for five seconds, shade dried and placed on wet cotton swab with filter paper in a Petri dish (50 $\mathrm{mm} \mathrm{dia).} \mathrm{The}$ cotton swab was moistened at regular intervals to avoid drying of leaves.

Three replications were maintained in each concentration in laboratory at $28 \pm 1{ }^{\circ} \mathrm{C}$ with $70 \pm 5$ per cent RH. Thirty $T$. urticae adults collected from base culture were released in each piece of leaf. The percent mortality was assessed after $24 \mathrm{~h}$ of release for each concentration. The moribund mites were counted as dead.

\section{Results and Discussion}

Soil is the commonest habitat for Streptomycetes, it is found in sub-surface layer of the soil, where organic matter is higher (Kutzner, 1986; Williams et al., 1989). Hence the soil samples were collected from sub-surface of selected area in the present study. The diversity of terrestrial actinomycetes is of extraordinary significance in several areas of science and agriculture, particularly in antibiotic production (Magarvey et al., 2004). The soil samples taken for this study were collected from two different locations i.e. Tamil Nadu and Maharashtra. Actinomycetes were isolated by pour plate technique following the serial dilution $\left(10^{-3}\right.$ and $\left.10^{-4}\right)$ of soil samples on Ken Knight's medium. Twenty six strains of actinomycetes were isolated from rhizosphere soils collected from the Tamil Nadu and Maharashtra.

Actinomycetes were isolated based on the colony morphology, colour, size, texture and powdery growth exhibited by the isolated organism after 7 days of incubation. Selected colonies (rough, chalky, dry) of actinomycetes were further isolated in pure form on the solidified Ken Knight Agar medium by streak plate method. Totally twenty six isolates of actinomycetes were isolated and named as (Actinobacteria) A1, A2, A3, A4, A5, A6, A7, A8, A9, A10, A11, A12, A13, A14, A15, A16, A17, A18, A19, A20, A21, A22, A23, A24, A25, A26 and A27 (Table 1). The test cultures A1 to A27 were taken for studying their acaridical activity. Preliminary screening revealed that five of the isolates were active against spider mite, Tetranychus urticae on okra. Out of the sixteen isolates A7 and A27 isolate showed highest activity against spider mite, Tetranychus urticae. The elite isolate A7 and A27 was selected for further study (Table 2 and Table 3). 
Table.1 Effectiveness of actinobacteria against Tetranychus urticae

\begin{tabular}{|c|c|c|c|c|c|c|c|c|c|c|c|c|c|c|c|c|}
\hline \multirow[b]{2}{*}{ Treatment } & \multicolumn{4}{|c|}{ 6hrs } & \multicolumn{4}{|c|}{24 hrs } & \multicolumn{4}{|c|}{ 48hrs } & \multicolumn{4}{|c|}{$72 \mathrm{hrs}$} \\
\hline & R1 & $\mathbf{R 2}$ & R3 & Mean & R1 & $\mathbf{R 2}$ & R3 & Mean & R1 & $\mathbf{R 2}$ & R3 & Mean & R1 & $\mathbf{R 2}$ & R3 & Mean \\
\hline A1 & 27 & 28 & 30 & 28.33 & 24 & 24 & 25 & 24.33 & 23 & 18 & 19 & 20.00 & 20 & 18 & 18 & 18.67 \\
\hline $\mathrm{A} 2$ & 26 & 30 & 27 & 27.67 & 20 & 24 & 22 & 22.00 & 15 & 19 & 20 & 18.00 & 15 & 17 & 20 & 17.33 \\
\hline A3 & 26 & 28 & 27 & 27.00 & 22 & 25 & 23 & 23.33 & 18 & 20 & 18 & 18.67 & 17 & 19 & 17 & 18.33 \\
\hline A4 & 28 & 25 & 27 & 26.67 & 24 & 22 & 21 & 22.33 & 17 & 18 & 16 & 17.00 & 16 & 18 & 14 & 16.00 \\
\hline A5 & 25 & 28 & 29 & 27.33 & 23 & 24 & 26 & 24.33 & 20 & 20 & 21 & 20.33 & 20 & 18 & 19 & 19.00 \\
\hline A6 & 29 & 29 & 28 & 28.67 & 14 & 21 & 15 & 16.67 & 11 & 10 & 8 & 9.67 & 7 & 5 & 0 & 4.00 \\
\hline A7 & 26 & 28 & 24 & 26.00 & 4 & 7 & 5 & 5.33 & 2 & 2 & 2 & 2.00 & 0 & 0 & 0 & 0.00 \\
\hline A8 & 25 & 21 & 23 & 23.00 & 12 & 13 & 9 & 11.33 & 8 & 6 & 5 & 6.33 & 2 & 2 & 3 & 2.33 \\
\hline A9 & 17 & 18 & 17 & 17.33 & 14 & 5 & 10 & 9.67 & 8 & 2 & 5 & 5.00 & 2 & 0 & 0 & 0.67 \\
\hline A10 & 15 & 18 & 15 & 16.00 & 6 & 5 & 2 & 4.33 & 2 & 1 & 3 & 2.00 & 1 & 0 & 1 & 0.67 \\
\hline A11 & 28 & 25 & 26 & 26.33 & 24 & 21 & 23 & 22.66 & 17 & 19 & 20 & 18.66 & 16 & 17 & 16 & 16.33 \\
\hline A12 & 27 & 28 & 26 & 27.00 & 5 & 8 & 6 & 6.33 & 3 & 5 & 4 & 4.00 & 2 & 1 & 0 & 1.00 \\
\hline A13 & 25 & 27 & 26 & 26.00 & 21 & 24 & 22 & 22.33 & 17 & 19 & 17 & 17.66 & 16 & 18 & 16 & 16.66 \\
\hline A14 & 27 & 24 & 26 & 25.66 & 23 & 21 & 20 & 21.33 & 16 & 17 & 15 & 16.00 & 15 & 17 & 13 & 15.00 \\
\hline A15 & 29 & 29 & 28 & 28.67 & 14 & 21 & 15 & 16.67 & 12 & 11 & 9 & 10.66 & 7 & 6 & 2 & 5.00 \\
\hline A16 & 20 & 23 & 24 & 22.33 & 15 & 13 & 18 & 15.33 & 20 & 23 & 24 & 22.33 & 2 & 1 & 0 & 1.00 \\
\hline A17 & 26 & 27 & 29 & 27.33 & 23 & 23 & 24 & 23.33 & 24 & 17 & 18 & 19.66 & 20 & 17 & 17 & 18.00 \\
\hline A18 & 25 & 29 & 26 & 26.66 & 20 & 23 & 21 & 21.33 & 16 & 18 & 19 & 17.66 & 14 & 16 & 21 & 17.00 \\
\hline A19 & 25 & 28 & 28 & 27.00 & 23 & 24 & 25 & 24.00 & 20 & 21 & 18 & 19.66 & 20 & 17 & 18 & 18.33 \\
\hline A20 & 28 & 25 & 26 & 26.33 & 24 & 21 & 23 & 22.66 & 17 & 19 & 20 & 18.66 & 16 & 17 & 16 & 16.33 \\
\hline A21 & 20 & 22 & 23 & 21.66 & 20 & 23 & 24 & 22.33 & 14 & 12 & 17 & 15.33 & 5 & 3 & 1 & 3.00 \\
\hline A22 & 26 & 27 & 30 & 27.66 & 24 & 25 & 27 & 25.33 & 21 & 20 & 22 & 21.00 & 21 & 18 & 19 & 19.33 \\
\hline A23 & 29 & 29 & 28 & 28.67 & 14 & 21 & 15 & 16.67 & 12 & 11 & 9 & 10.66 & 7 & 6 & 2 & 5.00 \\
\hline A24 & 24 & 26 & 27 & 25.66 & 22 & 23 & 24 & 23.00 & 18 & 19 & 16 & 17.66 & 17 & 14 & 14 & 15.00 \\
\hline A25 & 27 & 28 & 30 & 28.33 & 24 & 24 & 25 & 24.33 & 23 & 18 & 19 & 20.00 & 20 & 18 & 18 & 18.67 \\
\hline A26 & 25 & 21 & 23 & 23.00 & 12 & 13 & 9 & 11.33 & 8 & 6 & 5 & 6.33 & 2 & 2 & 3 & 2.33 \\
\hline A27 & 16 & 18 & 22 & 18.67 & 10 & 8 & 18 & 12.00 & 16 & 18 & 22 & 18.67 & $\mathbf{0}$ & 0 & 1 & 0.33 \\
\hline
\end{tabular}


Table.2 Evaluation of actinobacteria (A7) against okra mite Tetranychus urticae under laboratory condition

\begin{tabular}{|l|c|c|c|c|c|c|c|c|c|}
\hline \multirow{2}{*}{ Treatment } & \multirow{2}{*}{ Dose } & \multicolumn{4}{|c|}{ 6 hrs after treatment } & \multicolumn{4}{c|}{ 24 hrs after treatment } \\
\cline { 3 - 10 } & & $\mathbf{R}_{\mathbf{1}}$ & $\mathbf{R}_{\mathbf{2}}$ & $\mathbf{R}_{\mathbf{3}}$ & $\mathbf{M e a n}$ & $\mathbf{R}_{\mathbf{1}}$ & $\mathbf{R}_{\mathbf{2}}$ & $\mathbf{R}_{\mathbf{3}}$ & Mean \\
\hline 1\% (A7) & $5 \mathrm{ml}$ & 15 & 21 & 23 & 19.67 & 30 & 28 & 30 & 29.33 \\
\hline 1\% DMSO & $5 \mathrm{ml}$ & 10 & 13 & 14 & 12.33 & 27 & 26 & 27 & 26.67 \\
\hline 5\% (A7) & $5 \mathrm{ml}$ & 26 & 24 & 23 & 24.33 & 30 & 30 & 30 & 30.00 \\
\hline 5\% DMSO & $5 \mathrm{ml}$ & 15 & 16 & 10 & 13.67 & 28 & 27 & 28 & 27.67 \\
\hline
\end{tabular}

Number of dead mites after treatment, Number of mites treated 30 per replication, (A7) - Actinobacteria Culture, DMSO- Control

Table.3 Evaluation of actinobacteria (A27) against okra mite Tetranychus urticae under laboratory condition

\begin{tabular}{|l|c|c|c|c|c|c|c|c|c|}
\hline \multirow{2}{*}{ Treatment } & \multirow{2}{*}{ Dose } & \multicolumn{4}{|c|}{ 6 hrs after treatment } & \multicolumn{4}{c|}{ 24 hrs after treatment } \\
\cline { 3 - 10 } & & $\mathbf{R}_{\mathbf{1}}$ & $\mathbf{R}_{\mathbf{2}}$ & $\mathbf{R}_{\mathbf{3}}$ & $\mathbf{M e a n}$ & $\mathbf{R}_{\mathbf{1}}$ & $\mathbf{R}_{\mathbf{2}}$ & $\mathbf{R}_{\mathbf{3}}$ & Mean \\
\hline $1 \%(\mathrm{~A} 27)$ & $5 \mathrm{ml}$ & 12 & 19 & 17 & 16.00 & 25 & 23 & 25 & 24.33 \\
\hline $1 \%$ DMSO & $5 \mathrm{ml}$ & 8 & 10 & 12 & 10.00 & 21 & 22 & 20 & 21.00 \\
\hline $5 \%(\mathrm{~A} 27)$ & $5 \mathrm{ml}$ & 23 & 21 & 20 & 21.33 & 27 & 26 & 28 & 27.00 \\
\hline $5 \%$ DMSO & $5 \mathrm{ml}$ & 14 & 15 & 9 & 12.66 & 25 & 25 & 26 & 25.33 \\
\hline
\end{tabular}

Number of dead mites after treatment, Number of mites treated 30 per replication, (A27) - Actinobacteria Culture, DMSO- Control

Plate.1 Evaluation of actinomycete A7 culture against red spider mite Tetranychus urticae

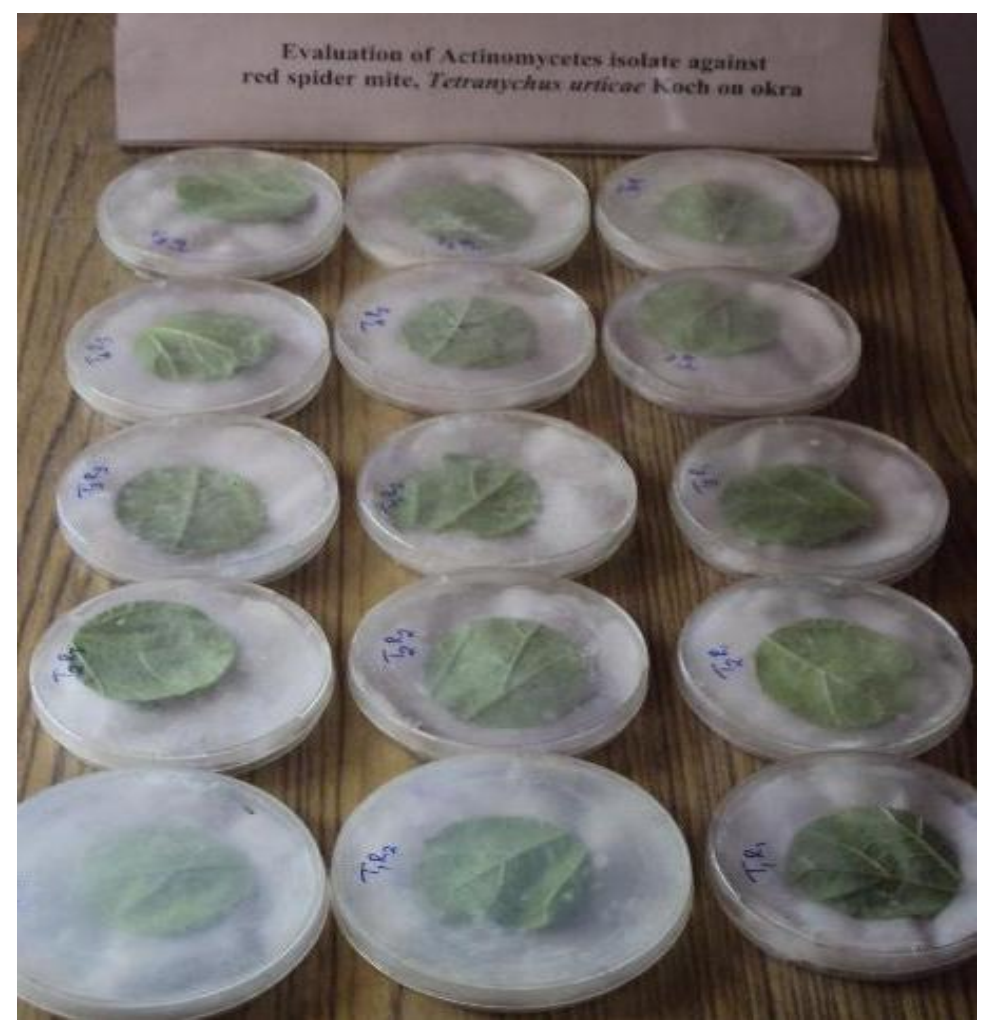




\section{Secondary metabolite production}

The isolates possessing antibacterial activity in both primary and secondary screening were selected for secondary metabolite production. Fermentation was carried out by the submerged state culture in Erlenmeyer flask under static condition $(1000 \mathrm{ml})$. The stock culture of the test actinomycetes used in this study was prepared by streaking the actinomycetes from the agar slants to Ken Knight agar medium. All compounds was added to the diluents and allowed to dissolve completely. The medium was then autoclaved at $121{ }^{\circ} \mathrm{C}$ and $15 \mathrm{lb}$ for 15 minutes and allowed to cool down to room temperature before being poured into $90 \mathrm{~mm}$ Petri dishes. The actinomycetes were streaked on the prepared medium and incubated at $28{ }^{\circ} \mathrm{C}$ for between 4 and 7 days under aerobic conditions. Actinomycetes inoculum was then prepared by transferring several colonies into sterile Soluble Starch (SS) broth $(100 \mathrm{ml})$. Incubated the medium for 4 days at room temperature. The Soluble Starch (SS) broth was prepared. One litter Erlenmeyer flasks sterilized by autoclaving at $121{ }^{\circ} \mathrm{C}$ and $15 \mathrm{lb}$ for 15 minutes. After the broth cooled, $100 \mathrm{ml}$ volumes of actinomycetes suspensions were used to inoculate the flasks.

The flasks were then incubated at $27{ }^{\circ} \mathrm{C}$ for 10 days. For quality control, confirmation of purity was done by streaking the fermentation cultures on nutrient agar (NA), potato dextrose agar (PDA) and ken knight agar plates. The antimicrobial compounds from crude extract were extracted with five different solvent viz., methanol (high polar), chloroform (medium polar), ethyl acetate (medium polar), Petroleum ether (non-polar) and Hexane (non-polar). To evaluate which particular solvent dissolves more secondary metabolites from crude extract. Solvents was added to the filtrate in the ratio of $1: 1(\mathrm{v} / \mathrm{v})$ and shaken vigorously for $1 \mathrm{~h}$ for complete extraction. Then with help of separating funnel the ethyl acetate phase that contains antibiotic was separated from the aqueous phase. The aliquot was concentrated in vacuo at $60{ }^{\circ} \mathrm{C}$ using a rotary flash vacuum evaporator.

\section{Mass production of A7 and A27 isolate}

The A7 and A27 mother culture was inoculate on the Ken Knight's broth and incubated at 28 ${ }^{\circ} \mathrm{C}$ for 4 to 7 days under aerobic conditions. Mass production of A7 and A27 culture carried out using soluble starch medium. The production medium inoculated with A7 and A27 culture at 5 percent level. The flasks were incubated at room temperature for 6-7 days. The bioactive secondary metabolites from crude extract were extracted with solvent ethyl acetate (medium polar). Solvents was added to the filtrate in the ratio of $1: 1(\mathrm{v} / \mathrm{v})$ and shaken vigorously for $1 \mathrm{~h}$ for complete extraction. Then with help of separating funnel the ethyl acetate phase that contains secondary metabolite was separated from the aqueous phase.

\section{Method of bioassay}

For studying the acute toxicity of A7 and A27 isolateagainst $T$. urticae, unifested leaves collected from okra plants were cut into pieces of $40 \mathrm{~mm}$ dia. size and dipped in acaricide solutions for five seconds, shade dried and placed on wet cotton swab with filter paper in a Petri dish (50 $\mathrm{mm}$ dia $)$. The cotton swab was moistened at regular intervals to avoid drying of leaves (Plate 1). Three replications were maintained in each concentration in laboratory at $28 \pm 1{ }^{0} \mathrm{C}$ with $70 \pm 5$ per cent RH. Thirty $T$. urticae adults collected from base culture were released in each piece of leaf. The percent mortality was assessed after $24 \mathrm{~h}$ of release for each concentration. The moribund mites were counted as dead. 
Effect of A7 and A27 culture filtrate on acaricidal activity against spider mite

The prepared soluble starch medium inoculated with the A7 and A27 culture at 5 percent level and incubated at room temperature for $6-7$ days. After the fermentation period the culture filtrate was separated from the fermentation medium by filtration. The bioactive secondary metabolites from crude extract were extracted with solvent ethyl acetate (medium polar). Solvents was added to the filtrate in the ratio of $1: 1(\mathrm{v} / \mathrm{v})$ and shaken vigorously for $1 \mathrm{~h}$ for complete extraction. Then with help of separating funnel the ethyl acetate phase that contains secondary metabolite was separated from the aqueous phase. The ethyl acetate concentrate was evaporated to dryness in Petri plates and dissolved in DMSO (Dimethyl Sulfoxide) for treatment purpose.

\section{References}

Cowan, S.T. 1974. Cowan and Steel Manual for the Identification of Medical Bacteria. $2^{\text {nd }}$ Edn. London: Cambridge University Press.

Ellaiah, P., B. Srinivasulu, K. Adinarayana. 2004. Optimisation studies on neomycin production by a mutant strain of Streptomyces marinensis in solid state fermentation process. Biochem., 39: 529-534.

Kanzaki H., S. Yanagisawa, and T. Nitoda. (2000). Biosynthetic intermediates of the tetradehydro cyclic dipeptide albonoursin produced by Streptomyces albulus KO-23. J. Antibiot. 53, 1257-
1264.

Kenneth, L.K. and B.J. Deane. 1955. Colour universal language and dictionary of names. United states Department of Commerce. National Bureau of standards. Washington, D. C., 20234.

Kulkarni, Y. and Aynihojri, Y. (1995). Isolation and characterization of actinomycetes and optimization of its production. MSc thesis, Department of Microbiology, University of Pune. India.

Kutzner, K.G. 1986. The family Streptomycetaceae. In Starr, M.P., Stolp, H., Trupir, H.G., Balows, A. And Schlegel, H.G. (ed.) The prokaryotes, A Handbook on Habitat, Isolation and Identification of Bacteria. Vol 2.Springer Verlag, Newyork. Pp.20882090.

Magarvey, N.A., J.M. Keller, V. Bernan, M. Dworkin and D.H. Sherman. 2004. Isolation and characterization of novel marine-derived Actinomycetes taxa rich in bioactive metabolites. App. Environ. Microbiol., 70(12): 7520-7529.

Suneetha V and Zaved AK (2011). Screening, Characterisation and Optimization of Microbial Pectinase, Soil Enzymology, Soil Biology-22, G. Shukla and A. Varma (eds) Springer- Verlag Berlin Heidelberg, 2011. pp. 329-337.

Tanaka, Y.T. and Omura, S. (1993). Agroactive compounds of microbial origin. Ann. Rev. Microbiol. 47: 57-87.

Williams, S. T. and T. Cross. 1971. Isolation, purification, cultivation and preservation of actinomycetes. Meth. Microbiol., 4: 295-334.

\section{How to cite this article:}

Rajesh Ramasamy, Jaivel Nanjundan and Marimuthu Ponnusamy. 2017. Screening, Isolation and Evaluation of Secondary Metabolite Producing Streptomyces against Spider Mite, Tetranychus urticae on Okra. Int.J.Curr.Microbiol.App.Sci. 6(11): 3058-3065. doi: https://doi.org/10.20546/ijcmas.2017.611.358 